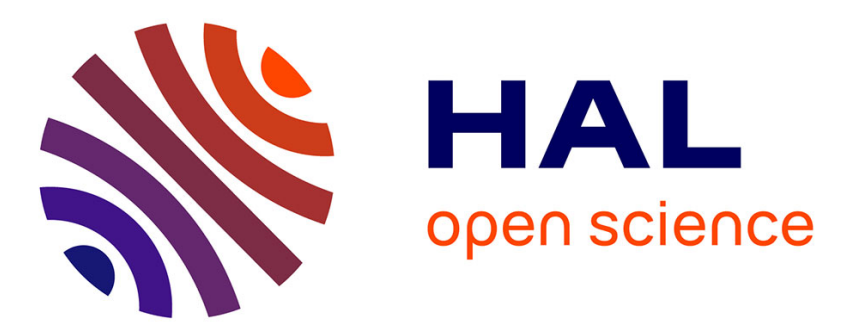

\title{
Fabrication of ultrathin MIL-96(Al) films and study of CO2 adsorption/desorption processes using quartz crystal microbalance
}

Miguel A Andrés, Marvin Benzaqui, Serre Christian, Nathalie Steunou, Ignacio Gascón

\section{To cite this version:}

Miguel A Andrés, Marvin Benzaqui, Serre Christian, Nathalie Steunou, Ignacio Gascón. Fabrication of ultrathin MIL-96(Al) films and study of CO2 adsorption/desorption processes using quartz crystal microbalance. Journal of Colloid and Interface Science, 2018, 519, pp.88-96. 10.1016/j.jcis.2018.02.058 . hal-03114366

\section{HAL Id: hal-03114366 \\ https://hal.science/hal-03114366}

Submitted on 18 Jan 2021

HAL is a multi-disciplinary open access archive for the deposit and dissemination of scientific research documents, whether they are published or not. The documents may come from teaching and research institutions in France or abroad, or from public or private research centers.
L'archive ouverte pluridisciplinaire $\mathbf{H A L}$, est destinée au dépôt et à la diffusion de documents scientifiques de niveau recherche, publiés ou non, émanant des établissements d'enseignement et de recherche français ou étrangers, des laboratoires publics ou privés. 


\title{
Fabrication of ultrathin MIL-96(Al) films and study of $\mathrm{CO}_{2}$ adsorption/ desorption processes using quartz crystal microbalance
}

Miguel A. Andrés ${ }^{a, b}$, M. Benzaqui ${ }^{\mathrm{d}, c}$, C. Serre ${ }^{\mathrm{d}, \mathrm{c}}$, N. Steunou ${ }^{\mathrm{d}}$, I. Gascón ${ }^{\mathrm{a}, \mathrm{b}, \pi}$

'Departamento de Química Física, Facultad de Ciencias, Universidad de Zaragoza, 50009 Zaragoza, Spain 'Instituto de Nanociencia de Aragón (INA), Universidad de Zaragoza, 50018 Zaragoza, Spain Institut des Matériaux Poreux de Paris, FRE 2000 CNRS Ecole Normale Supérieure de Paris, Ecole Supérieure de Physique et de Chimie Industrielles de Paris, PSL Research University, 75005 Paris, France 'Institut Lavoisier de Versailles, 45 avenue de États-Unis, Bâtiment Lavoisier, 78035 Versailles Cedex, France

\begin{abstract}
A B S T R A C T
This contribution reports the fabrication and characterization of ultrathin films of nanoparticles of the water stable microporous Al tricarboxylate metal organic framework MIL-96(Al). The preparation of MOF dispersions in chloroform has been optimized to obtain dense monolayer films of good quality, without nanoparticle agglomeration, at the air-water interface that can be deposited onto solid substrates of different nature without any previous substrate functionalization. The MOF studied shows great interest for $\mathrm{CO}_{2}$ capture because it presents $\mathrm{Al}^{3+}$ Lewis centers and hydroxyl groups that strongly interact with $\mathrm{CO}_{2}$ molecules. A comparative $\mathrm{CO}_{2}$ adsorption study on drop-cast, Langmuir-Blodgett (LB) and Langmuir-Schaefer (LS) films using a Quartz Crystal Microbalance-based setup (QCM) has revealed that the $\mathrm{CO}_{2}$ uptake depends strongly on the film fabrication procedure and the storage conditions. Noteworthy the $\mathrm{CO}_{2}$ adsorption capacity of LB films is increased by $30 \%$ using a simple and green treatment (immersion of the film into water during $12 \mathrm{~h}$ just after film preparation). Finally, the stability of LB MOF monolayers upon several $\mathrm{CO}_{2}$ adsorption/desorption cycles has been demonstrated, showing that $\mathrm{CO}_{2}$ can be easily desorbed from the films at $303 \mathrm{~K}$ by flowing an inert gas (He). These results show that MOF LB monolayers can be of great interest for the development of MOF-based devices that require the use of very small MOF quantities, especially gas sensors.
\end{abstract}


methodologies [3], functionalization processes [4], MOF properties [5] and composites containing MOFs [6] have been extensively studied and their potential applications in different sectors of industrial interest are still being widely explored: gas storage [7] membrane technology [8], heterogeneous catalysts [9], sensors [10], drug delivery [11], electronic devices [12], etc. Many of these applications [13] require an adequate shaping such as the formation of MOF films onto solid surfaces with precise control of film thickness and homogeneity [14]

Between the large number of processes reported to deposit MOF coatings onto solid substrates, SURMOFs [10] (surface-mounted metal organic frameworks) prepared by liquid phase epitaxy (LPE) are promising candidates due to the crystalline, high quality coatings with predefined orientations with respect to the substrate that are obtained [14]. However, this methodology suffers from several limitations: previous functionalization of the substrates by self-assembly of appropriate monolayer films is required and in general, it is a very time-demanding procedure. This strategy cannot be applied to all types of MOFs and has been, to date mainly restricted to low valence metal (II) based MOFs. This excludes water stable MOFs based on metals in higher oxidation states (III, IV) that are the most promising candidates for real applications.

In a recent study [15], some of us have reported the fabrication of Langmuir-Blodgett (LB) films of nanoparticles (NPs) of the mesoporous metal organic framework MIL-101(Cr), showing that compact MIOF LB films can be deposited onto different kind of substrates adding only $1 \mathrm{wt} \%$ of behenic acid to MOF dispersion in order to reduce particle aggregation and improve the interaction of the NPs with the surface of the solid supports. Particularly, these MIL-101(Cr) LB films (MOF content of only a few micrograms) deposited onto QCM crystals have been used to obtain accurate $\mathrm{CO}_{2}$ adsorption values, using much lower MOF quantities than conventional adsorption instruments.

MOF thin films deposited onto QCM substrates are very interesting systems for the development of chemical sensors [16] and also for the study of fundamental properties for the potential applications of MOFs, such as mass transfer processes and activation [17]. It has been proven that the outer surface of MOFs undergoes changes upon exposure to ambient conditions, resulting in the formation of surface barriers [18], which makes more difficult the access of guest molecules to the MOF pores. Surface barrier phenomenon also explains why diffusion coefficients reported for the same MOF may vary by several orders of magnitude for different samples of the same material, even restricting the comparison to the results reported by the same research group using the same synthetic method [17].

Following our research on the preparation of MOF ultrathin films using the LB technique, in this work, MIL-96(AI) NPs of size $200 \pm 50 \mathrm{~nm}$ have been synthesized and LB and LS films have been fabricated onto quartz, glass and OCM crystals. Interestingly, MIL-96(AI) does not require the use of any additional surfactant to obtain compact and uniform MOF monolayers that can be deposited onto substrates of different nature, in contrast to MIL-101(Cr) NPs that needed behenic acid to improve film homogeneity and adhesion to the substrates [15].

MIL-96(Al) is an aluminium trimesate MOF, made under hydro/solvothermal conditions, which exhibits a 3D structure comprised of Al octahedral units (chains, trimers) connected with the 1,3,5-benzenetricarboxilate ligand [19]. Contrarily to MIL-101 $(\mathrm{Cr})$ that presents large pores and cavities, MIL-96(A) is a narrow pore MOF that contains three different types of cavities: spherical cages (type A, cavity-free diameter ca. $11 \AA$ ), elongated cavities (type $\mathrm{B}$, dimensions $\approx 9.5 \times 12.6 \times 11.3 \AA$ ) and narrow cages (type $C$, dimensions $\approx 3.6 \times 4.5 \AA$ ) accessible through microporous windows. Moreover, recent studies have shown that the $2 \mathrm{D}$ pore structure is comprised of a " $\mathrm{zig}-\mathrm{zag}$ " channel system between cavities $B$ and $C$, while cavities of type $A$ are isolated within the struc ture [20]. Narrow pore MOFs present great interest because they can potentially address key challenges such as carbon capture and other separation processes [21]. The remarkable hydrotherma and thermal stability of MIL-96(AI) along with a good affinity for $\mathrm{CO}_{2}$ as a result of the presence of $\mathrm{Al}$ Lewis acid sites and $-\mathrm{OH}$ groups make this material of high interest for $\mathrm{CO}_{2}$ capture. In addition, its $\mathrm{CO}_{2}$ adsorption capacity in the presence of moisture is very attractive. In a recent study, the effect of adsorbed water on $\mathrm{CO}_{2}$ uptake was evaluated for 45 MOFs and it was concluded that although the $\mathrm{CO}_{2}$ adsorption capacity is reduced in the presence of water, MIL-96 (Al) exhibits the best $\mathrm{CO}_{2}$ uptake in presence of water of all the MIOFs analyzed [22]. Moreover, the enthalpy of adsorption for $\mathrm{CO}_{2}$ in MIL-96(Al) is lower $\left(30-35 \mathrm{~kJ} \mathrm{~mol}^{-1}\right.$ ) than for other highly efficient $\mathrm{CO}_{2}$ adsorbents. Moderate adsorption enthalpy suggests an easy reversibility of adsorption-desorption cycles and is highly desirable for the adsorbent regeneration process, reducing significantly energy costs, which is required for industrial operations $[20]$.

In this study, we have analyzed the $\mathrm{CO}_{2}$ adsorption capacity of QCM crystals coated with MIL-96(Al) films prepared both by dropcasting and the LB method to investigate the effect of using various solvents (methanol, chloroform, $n$-hexane) for the preparation of MOF dispersions, the storage of the films in different environments and the treatment for a more efficient MOF film activation. In addition, the stability of $\mathrm{LB}$ films upon successive $\mathrm{CO}_{2}$ adsorption/desorption cycles has been analyzed, showing that $\mathrm{CO}_{2}$ can be easily desorbed from MIL-96(Al) thin films at $303 \mathrm{~K}$ only flowing an inert gas (He), without any thermal treatment.

\section{Materials and methods}

2.1. MOF synthesis and characterization

Aluminum nitrate nonahydrate $(4.5 \mathrm{~g}, 12 \mathrm{mmol})$ from Merck (98.5\%) and trimesic acid $(2.52 \mathrm{~g}, 12 \mathrm{mmol})$ from Sigma Aldrich (95\%) were dissolved in $300 \mathrm{~mL}$ of a $\mathrm{H}_{2} \mathrm{O} / \mathrm{DMF}$ (volume:volume = 111) mixture. $N, N$-Dimethylformamide (DMF) was supplied by Sigma Aldrich (99.8\%). Acetic acid (1.68 mL, $30 \mathrm{mmol}$ ) from Sigma Aldrich (99.7\%) was added. After heating the solution under reflux for $16 \mathrm{~h}$, a white mixture was obtained and centrifuged at $14500 \mathrm{rpm}$ for $15 \mathrm{~min}$. It was then washed with deionized water $(30 \mathrm{~mL})$, one more time with a $\mathrm{H}_{2} \mathrm{O} / \mathrm{EtOH}(\mathrm{v}: \mathrm{v}=1 / 1)$ mixture $(30 \mathrm{~mL}$ ) and finally with EtOH $(30 \mathrm{~mL})$. The obtained white crystals were finally dried at room temperature.

$\mathrm{CO}_{2}$ adsorption isotherms of the NPs were measured with a Micromeritics ASAP 2020 equipment at $303 \mathrm{~K}$ using water as a coolant.

Powder X-Ray Diffraction (PXRD) was collected using a Bruker D8 diffractometer mounted with a rotating capillary $(\theta-2 \theta)$ with Cu radiation $\left(\lambda \mathrm{K}_{\alpha 1}=1.54059 \AA\right)$

Scanning Electron Microscope (SEM) images were taken at $10 \mathrm{kV}$ with a Field Emission Gun (FEG) column using a SEM Inspect F50 (FEI Company). All samples inspected at SEM were coated with a layer of platinum $(5-10 \mathrm{~nm})$

\subsection{Langmuir, Langmuir-Blodgett and Langmuir-Schaefer film} fabrication and characterization

Langmuir film formation was studied in a commercial Langmuir Teflon trough (NIMA, Model 702) with dimensions of $720 \times 100$ $\mathrm{mm}$ and a symmetrical double-barrier configuration. Surface pressure vs. area $(\pi-A)$, surface potential vs. area $(\Delta V-A)$ and Brewster Angle Microscopy (BAM) images were registered in this device. 
Another apparatus was used for Langmuir-Blodgett and Langmuir-Schaefer (LS) film fabrication. This was a KSV-NIMA trough, model 2000-System 3, with dimensions $775 \times 120 \mathrm{~mm}$ and a symmetrical double-barrier system.

These troughs were kept inside closed cabinets in a clean room at constant temperature $\left(20 \pm 1^{\circ} \mathrm{C}\right)$. In both cases, compression was performed at a constant speed of $6 \mathrm{~cm}^{2} \mathrm{~min}^{-1}$. Ultra-pure Milli-Q water $(\rho=18.2 \mathrm{M} \Omega \mathrm{cm}$ ) was used in all the experiments as subphase. Surface pressure was continuously monitored in both devices using Wilhelmy balances with a filter paper plate. BAM images were obtained with a KSV NIMA Micro BAM. This device uses a red laser $(50 \mathrm{~mW}, 659 \mathrm{~nm})$ with a fixed incidence angle of $53.1^{\circ}$ as light source. The spatial resolution of the optical system in the water surface plane is $6 \mu \mathrm{m}$ per pixel. Surface potential was registered using a KSV NIMA SPOT surface potential sensor.

Chloroform (Macron, >99.8\%) was used to prepare MIL-96(Al) suspensions. Different concentrations were tested $(0.2,0.5$ and $1.0 \mathrm{mg} \mathrm{mL}^{-1}$ ). Suspensions were prepared from dry powder using conventional ultrasonic bath or ultrasonic probe.

The conventional ultrasonic bath was a WiseClean WUC-A02H (Power Output $100 \mathrm{~W}$ ). $30 \mathrm{~min}$ of sonication were enough to disperse the material. The ultrasonication probe-type device was a Hielscher UP400S ultrasonic processor (Power Output $400 \mathrm{~W}$ ) Samples were ultrasonicated continuously for $30 \mathrm{~min}$ at $50 \%$ amplitude using an $\mathrm{H} 3$ type tip ( $3 \mathrm{~mm}$ diameter). In both cases, 15 min of additional conventional sonication were used before spreading the material onto the water subphase.

Dynamic Light Scattering (DLS) measurements were used to characterize MOF dispersions prepared with both ultrasonic devices. The instrument used was a Malvern Zetasizer Nano ZS ZEN3600 equipped with a $633 \mathrm{~nm}$ laser. Suspensions were measured using a square optical glass cuvette from Malvern (model PCS1115) with a total capacity of $3500 \mu \mathrm{L}$ and $10 \mathrm{~mm}$ optical path. Suspensions were sonicated for $10 \mathrm{~min}$ before measurement. Scattered light was detected at $173^{\circ}$ angle. Attenuator index, measurement position and number of runs accumulated on each measurement were automatically adjusted by the software to obtain a photon counting rate of ca. $200 \mathrm{kcps}$. A total of three measurements were performed for each sample.

Langmuir-Blodgett films were fabricated onto solid substrates (glass, silicon, quartz, OCM crystals) using the vertical dipping method at a vertical speed of $1 \mathrm{~mm} / \mathrm{min}$. In the cases specified, the surface of glass substrates was made hydrophobic by immersion into a solution of $1,1,1,3,3,3$-hexamethlydisilizane (Sigma Aldrich, 99.9\%) for $24 \mathrm{~h}$. Substrates were then rinsed with chloroform to remove the silane excess. Unless otherwise stated, transference was performed during substrate emersion.

Langmuir-Schaefer films were also fabricated onto solid substrates similar to those used on Langmuir-Blodgett film fabrication. The substrate was held horizontally and parallel to the water surface using a vacuum pump-based horizontal dipping clamp (KSV $\mathrm{KN}-0006$ ). The suction cap where the substrates were attached has a diameter of either $7 \mathrm{~mm}$ (for glass and quartz substrates) or $18 \mathrm{~mm}$ (for QCM crystals). When the desired surface pressure was reached, the substrate was approached to the surface at a vertical speed of $1 \mathrm{~mm} / \mathrm{min}$. Once the substrate touched the water surface, it was withdrawn at a vertical speed of $10 \mathrm{~mm} / \mathrm{min}$.

Drop-cast samples were fabricated spreading drop by drop ca. $150 \mu \mathrm{L}$ on top of glass substrates similar to those used on Langmuir-Blodgett film fabrication and OCM disks. Chloroform (Macron, >99.8\%), methanol (Sigma-Aldrich, 99.8\%) and $n$-hexane (Sigma-Aldrich, 99.0\%) were used to prepare the suspensions.

SEM images were taken at $10 \mathrm{kV}$ with a FEG column using a SEM Inspect F50 (FEI Company). All samples inspected at SEM were coated with a layer of platinum $(5-10 \mathrm{~nm})$.
UV-Vis spectra of LB films deposited onto quartz plates (Hellma Analytics, 665.000 -QS, $45 \mathrm{~mm} \times 12.5 \mathrm{~mm} \times 1.25 \mathrm{~mm}$ ) were registered using a Varian Cary 50 spectrophotometer. A normal incident angle with respect to the film plane was used. Solutions were measured using quartz cuvettes of $350 \mu \mathrm{L}$ with a light path of $1 \mathrm{~mm}$ (Hellma Analytics, 100-QS).

Grazing incidence X-ray diffraction (GIXRD) characterization of films deposited onto $\mathrm{Si}\left(\begin{array}{lll}1 & 0 & 0\end{array}\right)$ substrates was performed using a high resolution Empyrean diffractometer (PANalytical) equipped with a Pixcell 1D medipix 3 detector. Measurements were performed operating at $45 \mathrm{kV}$ (generator voltage) and a tube current of $40 \mathrm{~mA}$ ( $\mathrm{Cu} \mathrm{K} \alpha$ radiation) and the scans were collected in the open detector mode. The grazing incidence angle (between $0.13^{\circ}$ and $0.16^{\circ}$ ) was optimized for each sample before scan acquisition.

\section{3. oCM-based setup for gas adsorption studies}

A homemade QCM-based setup was used for gas adsorption measurements [15]. The setup consists of a stainless steel cell of about $200 \mathrm{~mL}$ total volume. Two AT-cut QCM crystals of a resonant frequency of $9 \mathrm{NHz}$ purchased from Inficon were mounted onto two chlorinated polyvinyl chloride (CPVC) $\mathrm{CHC}-15$ crystal holder (Inficon) inside the chamber. Each disk was fixed to the holder by means of one O-ring made from Viton and a stainless steel lock nut. Each holder was connected through a 2 SMB-SMB plug to an Inficon ROCM system with two Phase Lock Oscillators capable of working in the 5.1-10 $\mathrm{MHz}$ range. The operating range goes from $-25^{\circ} \mathrm{C}$ to $95^{\circ} \mathrm{C}$.

One of the crystals was uncoated and used as a reference to correct possible fluctuations during the measurement due to temperature, pressure or gas flow [23].

A total gas flow of $50 \mathrm{~mL}$ (STP). $\mathrm{min}^{-1}$ was used in all the measurements. Helium was used as diluting gas and $\mathrm{CO}_{2}$ as adsorbate Gas flows were controlled separately using two Alicat Scientific MC-1000SCCM-D/5M mass-flow controllers. The pressure inside the chamber was monitored using a pressure sensor. Temperature inside the chamber was measured by two thermocouples and adjusted by two electric resistors.

Before starting each measurement, the sample was outgassed at $353 \mathrm{~K}$ during $2 \mathrm{~h}$ under a constant flow of $50 \mathrm{~mL}$ (STP) $\mathrm{min}^{-1}$ of $\mathrm{He}$ and then cooled to $303 \mathrm{~K}$ maintaining the same He flow until a stable frequency was obtained. Adsorption measurements were performed at constant temperature $(303 \mathrm{~K})$ using five different partial pressures of $\mathrm{CO}_{2}$ in the gas mixture: $20 \%, 40 \%, 60 \%, 80 \%$ and $100 \%$ in volume. Before changing the gas mixture composition, frequency was allowed to stabilize. At the end of the measurement, pure He was flown to sweep $\mathrm{CO}_{2}$ and observe the recovery of the samples. Cycling $\mathrm{CO}_{2}$ adsorption/desorption experiments were performed at constant temperature $(303 \mathrm{~K})$ and the same flow and gas mixtures described above were used. Pure He between cycles was flown until frequency stabilized.

\section{Results and discussion}

3.1. Langmuir, Langmuir-Blodgett and Langmuir-Schaefer films

Spherical MOF NPs of size $200 \pm 50 \mathrm{~nm}$ (Supplementary material, Fig. S1) were synthesized following the procedure described above and used for suspension preparation. Lanomuir films of MIL-96(Al) were obtained at the air-water interface spreading different volumes of diluted MOF NP suspensions in chloroform (concentrations used were $0.2,0.5$ and $1 \mathrm{mg} \mathrm{mL}^{-1}$ ). Initial experiments ( $\pi-A$ isotherms and UV-Vis spectra of the solutions) using suspensions prepared with the conventional ultrasonic bath showed a bad reproducibility even for solutions containing the 
same concentration of MOF. In addition, very compressed $\pi-A$ isotherms were obtained even for high spreading volumes $(8 \mathrm{~mL}$ of a $0.2 \mathrm{mg} \mathrm{mL}^{-1}$ solution). Using higher sonication times, more expanded $\pi-A$ isotherms were obtained (Supplementary material, Fig. S2)

Brewster Angle Microscopy images were taken spreading a 0.2 $\mathrm{mg} \mathrm{mL}^{-1}$ MLL-96(Al) suspension (Fig 1). Particle domains of about $450 \mu \mathrm{m}$ can be seen even from the start of the experiment (with the barriers completely opened), confirming particle aggregation. These domains finally coalesce into a film at low surface pressure values $\left(0.7 \mathrm{mN} \mathrm{m}^{-1}\right)$. Drop-cast samples of these solutions were analyzed by SEM (Supplementary material, Fig. S3) and confirmed the presence of big aggregates.

Ultrasonic probe was used in following experiments to break more efficiently the aggregates [24]. In comparison to conventional ultrasonic baths, higher ultrasonic intensities are applied to the suspension thanks to the use of the ultrasonic probe (the ultrasonication intensity can be expected to be up to 100 times greater) [25]. Dynamic light scattering measurements of the most diluted suspensions $\left(0.2 \mathrm{mg} \mathrm{mL}^{-1}\right)$ prepared using the ultrasonic probe showed a low polydispersity index (PDI) and monomodal size distributions (PDI $0.026 \pm 0.008$, average size $220.4 \pm 49.69 \mathrm{~nm}$ ) while suspensions of the same concentration prepared using conventional ultrasound bath showed a higher polydispersity index and bimodal size distributions (PDI $0.438 \pm 0.024$, Peak 1: Av. Size $263.7 \pm 73.43 \mathrm{~nm}, 97.1 \%$ intensity; Peak 2: Av. Size $5387 \pm 318.4 \mathrm{~nm}, 2.9 \%$ intensity), as deducted from the plots of size distribution based on intensity (Supplementary material, Fig. S4). These observations suggested that optimal MOF suspensions are obtained using the ultrasonic probe and a MOF concentration of $0.2 \mathrm{mg} \mathrm{mL}^{-1}$. Moreover, DLS measurements demonstrate that the use of the ultrasonic probe does not produce any ripening of MOF nanoparticles, contrarily to previous findings for ZIF- $8(\mathrm{Zn})$ [26].

Using this methodology for suspension preparation, different volumes of different samples of the same concentration $(0.2 \mathrm{mg}$ $\mathrm{mL}^{-1}$ ) can be spread, leading to reproducible $\pi-A$ isotherms (Supplementary material, Fig. S5). Also drop-cast samples inspected by SEM confirmed the decrease in agglomeration (Supplementary material, Fig. S6).
BAM images were obtained during film compression (Fig. 2) and did not show any domains until lower areas on the surface were reached $\left(140 \mathrm{~cm}^{2} \mathrm{mg}^{-1}\right)$. At low surface pressures $\left(1.0 \mathrm{mN} \mathrm{m}^{-1}\right)$ a film can be already observed although holes are present. Further compression leads to a more compact film. At $40 \mathrm{mN} \mathrm{m}^{-1}$, multilayering occurs.

$\Delta V-A$ isotherms are consistent with the formation of a compact film (Fig. 3). Surface potential oscillations at large areas per MOF mass reflect the existence of uncovered water surface areas as seen in BAM images. The start of slope growth over $140 \mathrm{~cm}^{2} \mathrm{mg}^{-1}$, at larger areas than the lift-off of the surface pressure [27], anticipates the beginning of film formation. A new slope change can be observed around $60 \mathrm{~cm}^{2} \mathrm{~g}^{-1}$. Further compression almost does not change $\Delta V$ value, probably due to the collapse of the film and the formation of 3D aggregates, according to the BAM images.

Langmuir films obtained with $0.2 \mathrm{mg} \mathrm{mL}^{-1}$ suspensions in chloroform were then transferred onto glass substrates for SEM inspec tion to assess the effect of suspension preparation and transfer pressure. Firstly, LB films were transferred at $30 \mathrm{mN} \mathrm{m}^{-1}$ during emersion using suspensions prepared with conventional ultrasound and ultrasonic probe. LB samples fabricated using mixtures prepared with conventional ultrasound bath showed greater particle aggregation than those prepared with ultrasonic probe (Fig. 4).

The effect of transfer pressure was analyzed using three different values (20,30 and $\left.40 \mathrm{mN} \mathrm{m}^{-1}\right)$. Films were transferred during substrate emersion. Almost defect-free LB monolayer films were obtained without adding any stabilizing species (e.g. surfactants). Surface coverage obtained by SEM characterization at the three surface pressure values was very similar, confirming that the film is in a dense condensed state (Supplementary material, Fig. S7) although stability measurements performed showed that Langmuir films are more stable at $30 \mathrm{mN} \mathrm{m}^{-1}$.

To study the effect of the substrate nature onto the MOF film deposition, Langmuir films fabricated at optimal conditions (trans ferred at $30 \mathrm{mN} \mathrm{m}^{-1}$ using suspensions prepared with ultrasonic probe) were transferred during immersion of hydrophobic or untreated glass substrates (hydrophilic) leading to bad quality films with a low coverage (Supplementary material, Fig. S8). These experiments showed that the most favorable way for MIL-96(Al) LB film fabrication is the transfer during emersion of the hydrophilic
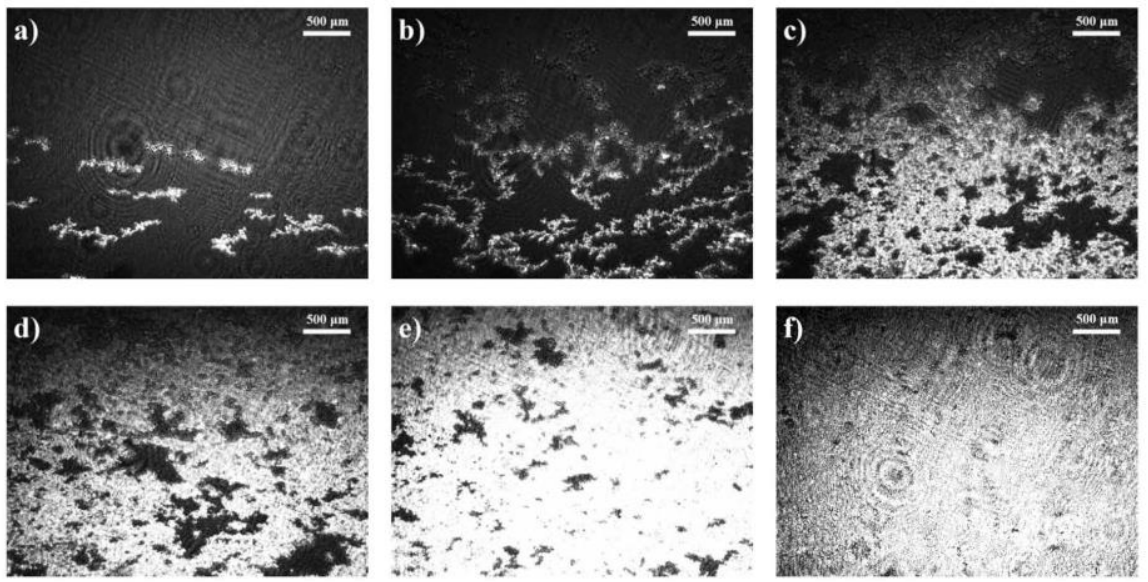

Fig 1. BAM images obtained at different surface pressures using a $0.2 \mathrm{mg} \mathrm{ml}^{-1} \mathrm{MIL}-96$ (A) suspension prepared using ultrasonic bath: (a) $0.0 \mathrm{mN} \mathrm{m}^{-1}\left(947 \mathrm{~cm}^{2} \mathrm{~g} \mathrm{MOF}^{-1}\right)$ (b) $0.0 \mathrm{~m} \mathrm{~m}^{-1}\left(413 \mathrm{~cm}^{2} \mathrm{~g} \mathrm{MOF}^{-1}\right)$, (c) $0.0 \mathrm{mN} \mathrm{m}^{-1}\left(338 \mathrm{~cm}^{2} \mathrm{~g} \mathrm{MOF}^{-1}\right)$ (d) $0.7 \mathrm{~m} \mathrm{~N} \mathrm{~m}^{-1}$ (e) $17.1 \mathrm{~m} \mathrm{~N} \mathrm{~m}^{-1}$ (f) $42.8 \mathrm{~m} \mathrm{~N} \mathrm{~m}^{-1}$ 

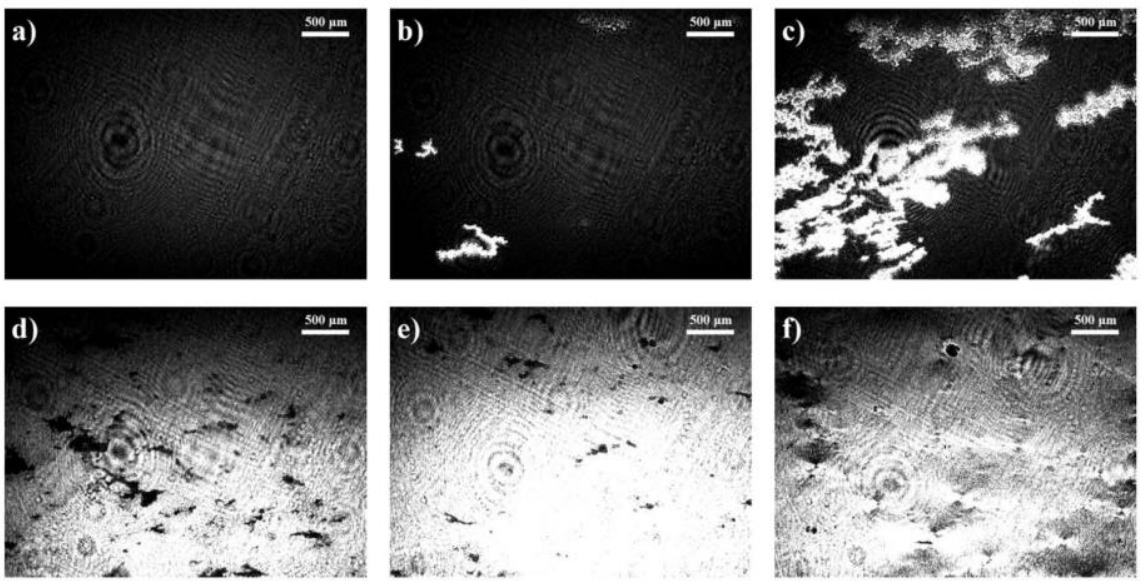

Fig. 2. BAM images obtained using a $0.2 \mathrm{mg} \mathrm{mL}^{-1} \mathrm{MIL}-96$ (Al) suspension prepared using ultrasonic probe: (a) $0.0 \mathrm{mN} \mathrm{m}^{-1}\left(480 \mathrm{~cm}^{2} \mathrm{~g} \mathrm{MOF}^{-1}\right)$, (b) $0.0 \mathrm{mN} \mathrm{m}^{-1}$ (134 $\mathrm{cm}^{2} \mathrm{~g} \mathrm{MOF}^{-1}$ ), (c) $0.4 \mathrm{mN} \mathrm{m}^{-1}$ (101 $\mathrm{cm}^{2} \mathrm{~g} \mathrm{MOF}^{-1}$ ), (d) $1.5 \mathrm{mN} \mathrm{m}^{-1}$, (e) $15.0 \mathrm{mN} \mathrm{m}^{-1}$, (f) $46.0 \mathrm{mN} \mathrm{m}^{-1}$.

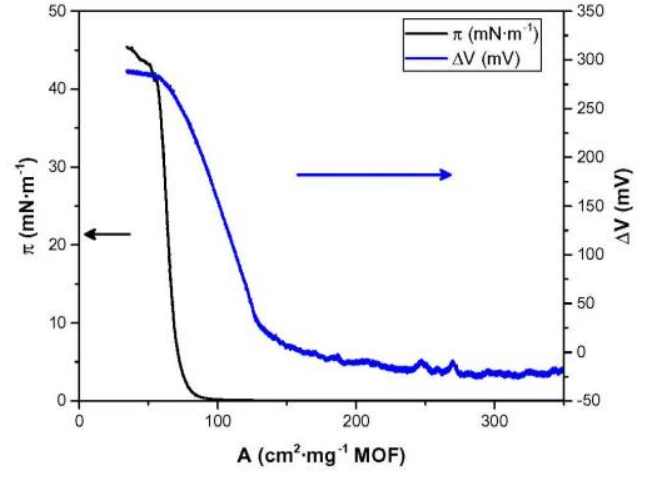

Fig. 3. $\Delta V-A$ isotherm for a $0.2 \mathrm{mg} \mathrm{mL}^{-1}$ ultrasonicated suspension of Mll-96(Al). For comparison purposes, the corresponding $\pi-A$ isotherm is also shown.

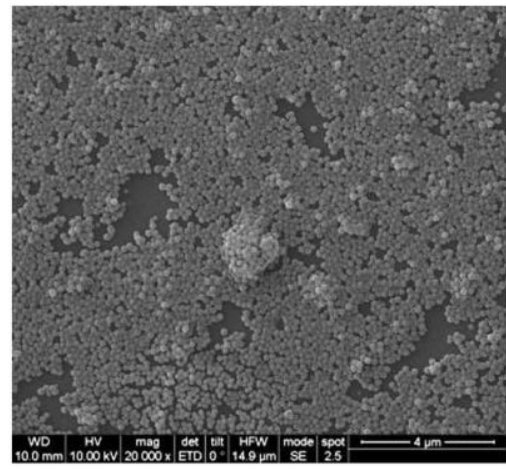

substrate. Finally, LS films were also deposited onto untreated glass substrates, showing a similar coverage than LB films transferred during emersion of the hydrophilic substrate.

To complete the characterization of the samples, LB films were transferred at a surface pressure value of $30 \mathrm{mN} \mathrm{m}^{-1}$ onto quartz

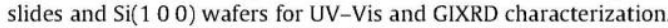
UV-Vis spectrum of the LB film (1 layer) showed a well-defined and intense absorption peak at $227 \mathrm{~nm}$ (Fig. 5). This results from the overlapping of the two observed peaks on $\mathrm{MeOH}$ solutions ( 233 and $246 \mathrm{~nm}$ ) and can be assigned to $\pi-\pi^{*}$ transitions on the 1,3,5-benzenetricarboxylate rings [28,29].

The GIXRD patterns of the drop-cast and LB/LS films (Fig. 6) show the characteristic pattern of MIL-96(Al) in agreement with the theoretical pattern $[19,20]$. This indicates that the crystalline structure of the MOF is preserved upon film fabrication.

The small amount of material deposited in the samples, probably makes that some of the diffraction peaks are less marked. In addition, the small size of the NPs leads, as expected, to broader diffraction peaks.

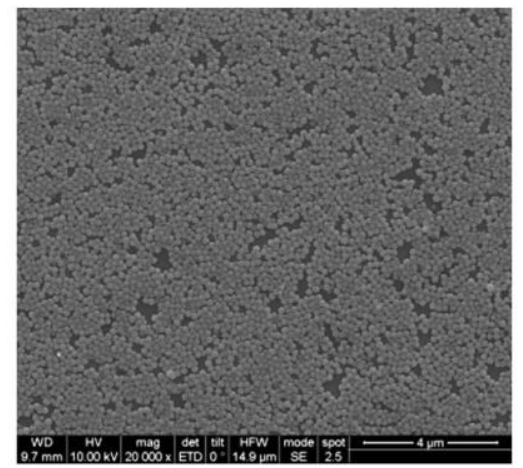

Fig. 4. SEM images of LB films transferred at $30 \mathrm{mN} \mathrm{m}^{-1}$ onto glass substrates. Spreading solutions were prepared using conventional ultrasound bath (left) or ultrasonic probe (right). Scale bar corresponds to $4 \mu \mathrm{m}$. 


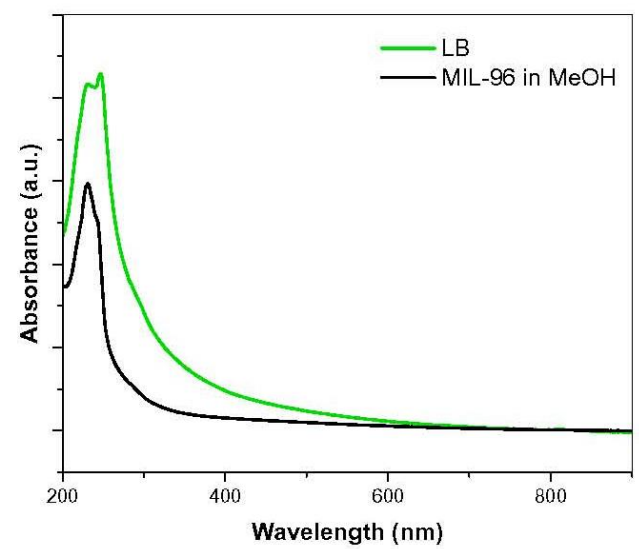

Fig. 5. UV-vis spectra of an LB film transferred at $30 \mathrm{mN} \mathrm{m}^{\mathbf{1}}$ onco a quartz slide (green line) and a ML-96(Al) solution in MeOH (black line). (For interpretation of the references to colour in this figure legend, the reader is referred to the web version of this article.)

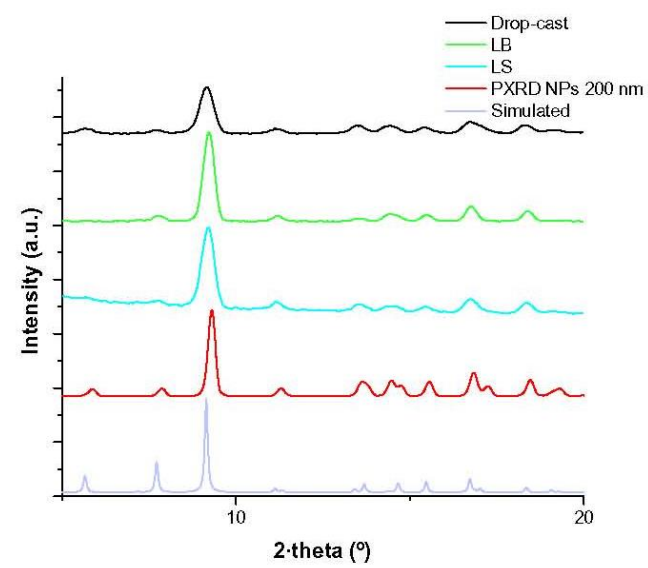

Fig. 6. GIXRD patterns of LB (green line), LS (blue line) and drop-cast (black line) samples of MIL-96(Al). For comparison purposes, a simulated spectrum for the powder (pale blue) and the experimental powder diffraction (PXRD, red line) are included. (For interpretation of the references to colour in this figure legend, the reader is referred to the web version of this article.

\section{2. $\mathrm{CO}_{2}$ adsorption studies}

$\mathrm{CO}_{2}$ adsorption studies at $303 \mathrm{~K}$ were performed using the QCM-based setup following the procedure described above. LB and LS films were studied together with drop-cast samples prepared using suspensions containing different solvents.

At least three different samples of each type were analyzed and average values together with error bars are plotted. Error bars in some points are almost not visible because of the size of the symbols. Mass changes were calculated from frequency changes using the Sauerbrey equation [30], $\Delta f=-C_{f} \Delta m$, where $\Delta f$ is the observed frequency change in $\mathrm{Hz}, C_{f}$ is the sensitivity factor of the QCM crystal $\left(0.1834 \mathrm{~Hz} \mathrm{ng}^{-1} \mathrm{~cm}^{2}\right.$, provided by Inficon $)$ and $\Delta m$ is the change in mass per unit area. The change in the resonant frequency after the deposition of the film was used to determine the mass of $\mathrm{MOF}$ deposited. Changes in the frequency upon varying $\mathrm{CO}_{2}$ content in the stream were used to determine the amount of $\mathrm{CO}_{2}$ adsorbed. In addition, sample recovery was analyzed by the frequency change after flowing pure $\mathrm{He}$ and the frequency value at the beginning of the experiment, before introducing $\mathrm{CO}_{2}$ on the chamber.

Langmuir films obtained at the best working conditions $(0.2$ $\mathrm{mg} \mathrm{mL}^{-1}$ MIL-96(AI) suspensions in chloroform prepared using ultrasonic probe) were transferred vertically (LB) or horizontally (LS) onto QCM substrates at $30 \mathrm{mN} \mathrm{m}^{-1}$. SEM characterization (Supplementary Material, Fig. S9) showed that a good surface coverage was obtained with both transfer methods, without the addition of any surfactant, contrarily to the behavior observed for MIL-101(Cr) NP that needed behenic acid to be efficiently deposited onto QCM substrates [15].

Fig. 7 shows $\mathrm{CO}_{2}$ adsorption isotherms obtained for $\mathrm{LB}$ and $\mathrm{LS}$ films and drop-cast samples prepared from chloroform suspensions using the QCM-based setup. These results are compared with the $\mathrm{CO}_{2}$ adsorption isotherm obtained for the powder sample using the conventional analytical method (Micromeritics ASP 2020 equipment). As can be observed, the $\mathrm{CO}_{2}$ adsorption on the powder sample is significantly higher than adsorption on the films. The lower $\mathrm{CO}_{2}$ uptakes obtained for all the samples studied in the QCM-based device can be explained by the different activation conditions between both methods: in the QCM-based setup temperature upper limit is $95^{\circ} \mathrm{C}$ and an inert gas flow is used to sweep the adsorbents. However, in the Micromeritics ASAP 2020 the sample is activated overnight at $150^{\circ} \mathrm{C}$ and outgassing is performed under secondary vacuum. As can be observed, LB and LS films show similar $\mathrm{CO}_{2}$ uptakes, which are more than two times higher than adsorption on drop-cast samples. This increment in gas adsorption was interpreted as a more effective activation in the cell of the LB and LS films compared to drop-cast films, due to the lower NP agglomeration in the LB/LS films, or to the exchange of adsorbates or solvent trapped into the material during LB/LS film preparation, since MOF NPS are floating onto the water surface during ca. $2 \mathrm{~h}$ before the films are transferred onto the substrates.

Interestingly, samples could be regenerated in our experimental QCM setup by flowing pure He without needing to increase the

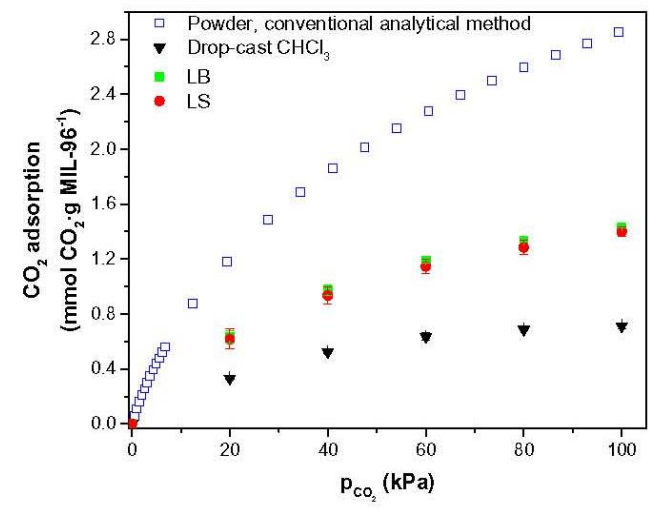

Fig. 7. $\mathrm{CO}_{2}$ adsorption isotherms on MIL-96(Al) films determined using the QCMbased device: $\mathrm{LB}$ film (green $\mathbf{m}$ ), LS film (red $\bullet$ ) and $\mathrm{CHCl}_{3}$ suspension drop-cast (black $\mathbf{V}$ ). Adsorption for the powder determined with a Micromeritics ASAP 2020 equipment is also plotted for comparison purposes (blue $\square$ ). Error bars are standard de vations obtained from the analysis of at least three samples. (For interpretation version of this article.) 
temperature. A recovery of $97-99 \%$ was obtained from the frequency change. To illustrate this behavior, a frequency vs. time curve for an adsorption experiment performed on a MIL-96(AI) LB film can be found on Supplementary material, Fig. S10.

In order to check if these values could be improved, drop-cast samples were prepared from suspensions in other volatile solvents ( $n$-hexane and methanol) which can also be used for Langmuir film fabrication. As shown in Fig. 8, the use of $n$-hexane did not improve $\mathrm{CO}_{2}$ adsorption whereas drop-cast samples from methanol suspensions gave rise to adsorption values almost two times higher than those obtained with chloroform suspensions, probably due to the differences of kinetic diameters and boiling points of the solvents as well as their hydrophilic/hydrophobic character; altogether this impacts the amount of adsorbed residual molecules into the pores that might restrict the pore accessibility, particularly for type B and C cavities.

Considering their molecular size, the three solvents used for suspension preparation shall be adsorbed on isolated type A and type $B$ cavities, on the outer surface of the MOF particles. $n$ Hexane has the highest boiling point $\left(69^{\circ} \mathrm{C}\right)$ and an intermediate kinetic diameter $(5.1 \AA)$, chloroform shows the highest kinetic diameter $(6.9 \AA)$ and the lowest boiling point $\left(61^{\circ} \mathrm{C}\right)$. Finally, methanol presents the lowest kinetic diameter $(3.6 \AA)$ and an intermediate boiling point $\left(65^{\circ} \mathrm{C}\right)$. In addition, $n$-hexane adsorption and confinement into the pores is governed by Van der Waals interactions, which can lead to higher adsorption enthalpies (30$100 \mathrm{~kJ} \mathrm{~mol}^{-1}$ ) [31] than for chloroform and methanol. Although chloroform shows a boiling point low enough to be desorbed at $80^{\circ} \mathrm{C}$, its larger size makes difficult its complete desorption during the activation step used in the QCM-based setup, while the higher boiling temperature and adsorption enthalpy of $n$-hexane combined with its kinetic diameter leads to the lower adsorption capacity of the drop-cast samples. On the other hand, the kinetic diameter of methanol makes easier its desorption during the film activation step. Moreover, as reported before, polar molecules able to form hydrogen bonds with the $-\mathrm{OH}$ groups in the metal clusters (e.g. short chain alcohols), can lead to an enhanced $\mathrm{CO}_{2}$ adsorption [32]. However, for hydrophobic solvents ( $n$-hexane and chloroform) no enhancement of $\mathrm{CO}_{2}$ adsorption by interaction with

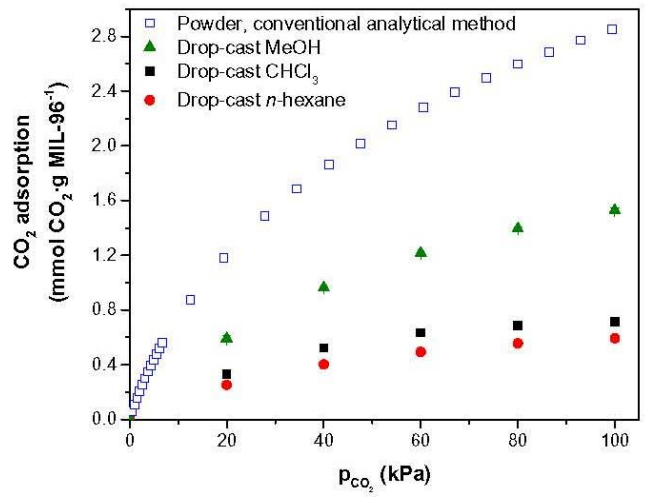

Fig. 8. $\mathrm{CO}_{2}$ adsorption isotherms on drop-cast samples prepared from suspensions of $\mathrm{MIL}-96$ ( $\mathrm{Al}$ ) in $\mathrm{CHCl}_{3}$ (black ) $\mathrm{MeOH}$ (green $\mathbf{4}$ ) and $n$-hexane (red determined using the QCM-based device. Error bars are standard deviations obtained from the analysis of at least three samples. Adsorption for the powder determined with a Micromeritics ASAP 2020 equipment is also plotted for comparison purposes (blue ㅁ). (For interpretation. of the references to colour in this figure legend, the reader is referred to the web version of this article.) adsorbed molecules is expected and the overall effect is a decrease on the number of adsorption sites for $\mathrm{CO}_{2}$. Therefore, residual chloroform and $n$-hexane molecules do not contribute to increase $\mathrm{CO}_{2}$ adsorption whereas $\mathrm{MeOH}$ might improve it.

In view of these results, new LB samples were deposited onto QCM disks in the same conditions described above and immersed immediately after preparation into methanol overnight $(12 \mathrm{~h})$ (Fig. 9). Noteworthy, gas adsorption was increased up to 1.85 mmol of $\mathrm{CO}_{2}$ per $\mathrm{g}$ of MOF (almost 33\% higher than untreated LB samples). As discussed above, methanol and chloroform are totally miscible but methanol is evacuated more efficiently during activation process, leading to larger pore volume accessible for gas adsorption; moreover, residual adsorbed methanol molecules, if any, might contribute to an enhanced $\mathrm{CO}_{2}$ adsorption. Longer immersion times of the films into methanol $(41 \mathrm{~h})$ led to similar results.

In order to explore greener alternatives, the same procedure was performed but films were immersed into water instead of methanol. An analogue effect was observed when the samples were immersed for $12 \mathrm{~h}$ into water (adsorption increased up to $1.82 \mathrm{mmol}$ of $\mathrm{CO}_{2}$ per $\mathrm{g}$ of $\mathrm{MOF}$ ). Drop-cast samples, prepared from solutions in chloroform and $n$-hexane, were also immersed during $12 \mathrm{~h}$ in water and a significant increment of $\mathrm{CO}_{2}$ uptake was observed. Fig. 9 summarizes all these results.

As can be observed in Fig. 9, $n$-Hexane drop-cast samples wer activated less efficiently in comparison to the chloroform samples as it was expected from the solubility values in water, since chloroform solubility in water is much higher $(8 \mathrm{~g} / \mathrm{L}$ of water for chloroform and $0.14 \mathrm{~g} / \mathrm{L}$ of water for $n$-hexane) leading to more efficient solvent exchange for the chloroform drop-cast samples.

In order to study the influence of storage conditions, new LB samples were prepared and stored in desiccator or in open cases. Samples stored in desiccator for short times (7 days) remained unaltered, whereas samples exposed to air showed a significant decrease of the $\mathrm{CO}_{2}$ uptake ( $30 \%$ decrease for a sample exposed 10 days to air). Storage for a long time in desiccator ( 65 days) leads to the same decrease in the adsorption capacity. All these results are shown in Fig. 10. This behavior was interpreted as the formation of surface barriers when MOF NPs are exposed to ambient con-

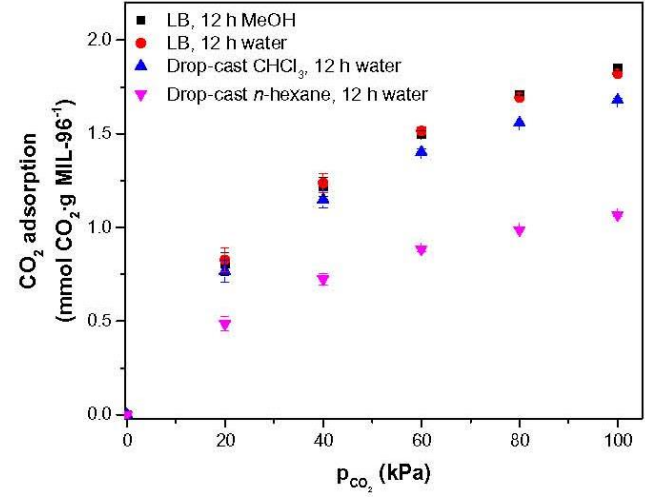

Fig. 9. $\mathrm{CO}_{2}$ adsorption isotherms for MIL-96(Al) films determined using the QCMbased device: $\mathrm{LB}$ film (red $\bullet$ ) drop-cast in $\mathrm{CHCl}_{3}$ (blue $\mathbf{4}$ ) and drop-cast in $n$-hexane (pink $\mathbf{V}$ ), immersed $12 \mathrm{~h}$ in water. A plot for LB samples immersed for $12 \mathrm{~h}$ in MeOH (black $\mathbf{m}$ ) is also included for comparison purposes. Error bars are standar deviations obtained from the analysis of at least three samples. (For interpretation of the references to colour in this figure legend, the reader is referred to the web version of this article.) 
ditions [17]. Many MOFs are non-water stable and their exposure to water vapor produces the surface barrier phenomenon, which limits diffusion of molecules into the pores. Interestingly, this process is almost reversible for the hydrophilic MIL-96(Al). Immersion of aged $\mathrm{LB}$ samples into water for $12 \mathrm{~h}$ allows obtaining similar $\mathrm{CO}_{2}$ adsorption values $\left(1.76 \mathrm{mmol}\right.$ of $\mathrm{CO}_{2} \mathrm{~g} \mathrm{MOF}^{-1}$ ) than $\mathrm{LB}$ samples treated just after preparation. Moreover, these adsorption values are higher than those of untreated $\mathbf{L B}$ samples measured immediately after preparation $\left(1.40 \mathrm{mmol}\right.$ of $\left.\mathrm{CO}_{2} \cdot \mathrm{g} \mathrm{MOF}^{-1}\right)$. The role of water in this process could be both to exchange with retained chloroform and an almost complete suppression of the surface barriers. In order to investigate the effect of this treatment on the films, samples immersed during $12 \mathrm{~h}$ in water or methanol were inspected by SEM but no structural changes were observed in the films. This seems to confirm that the treatment mainly produce the release of molecules trapped on the outer surface of the NPs.

The ageing of the LB samples treated with $\mathrm{MeOH}$ was also analyzed. A higher adsorption capacity was observed compared to the untreated aged samples $\left(1.25 \mathrm{mmol}\right.$ of $\mathrm{CO}_{2} \cdot \mathrm{g} \mathrm{MOF}^{-1}$ for the aged treated samples). A similar effect was observed for LB samples treated with water $\left(1.29 \mathrm{mmol}\right.$ of $\mathrm{CO}_{2} \cdot \mathrm{g} \mathrm{MOF}^{-1}$ for the aged treated samples), probably due to the removal of chloroform adsorbed into the pores of the material in the presence of $\mathrm{MeOH}$ or water.

In order to test additional procedures for a better activation of the films in the QCM-based cell, new LB samples were prepared and introduced into an oven for $21 \mathrm{~h}$ at $150^{\circ} \mathrm{C}$ immediately after preparation. Then, the samples were immersed into methanol during $12 \mathrm{~h}$. This strategy however did not work as expected and similar adsorption values to that of untreated LB samples were obtained ( $1.45 \mathrm{mmol}$ of $\mathrm{CO}_{2} \cdot \mathrm{g} \mathrm{MOF}{ }^{-1}$ ). This confirms the superiority of our method that is based on a less time- or energydemanding procedure in comparison to classical activation methods that require elevated temperatures.

Finally, several $\mathrm{CO}_{2}$ adsorption/desorption cycles were performed on recently prepared $\mathrm{LB}$ samples to study their stability, in order to evaluate the utility of LB films in a practical application (reusable $\mathrm{CO}_{2}$ gas sensors). Between each adsorption cycle, pure $\mathrm{He}$ flow was used to desorb $\mathrm{CO}_{2}$ from the MOF films. For practical purposes, 15 cycles were carried out. Fig. 11 summarizes the results obtained in these studies. Mloreover, the same experiment was also

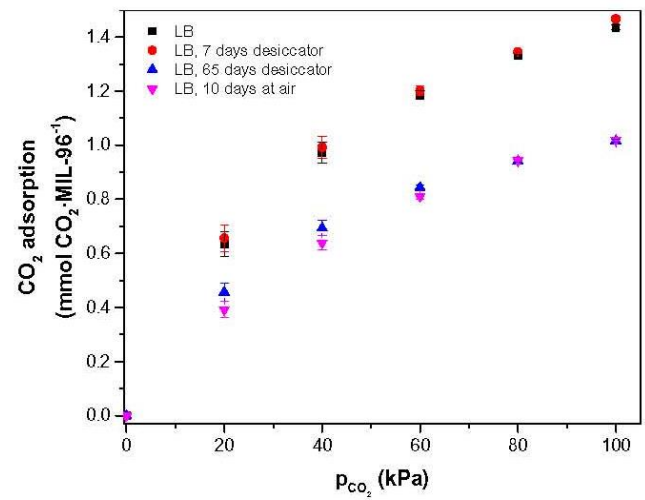

Fig. 10. $\mathrm{CO}_{2}$ adsorption isotherms for $\mathrm{LB}$ samples stored under different condition determined using the QCM-based device: 7 days at desiccator (red $\bullet$ ), 65 days at desiccator (blue 4 ) and 10 days at air (pink $\mathbf{}$ ). For comparison purposes, the adsorption for LB samples measured immediately after preparation (black $\mathbf{D}$ ) is shown. Error bars are standard devations obtained from the analysis of at least three samples. (For interpretation of the references to colour in this figure legend the reader is referred to the web version of this article.)

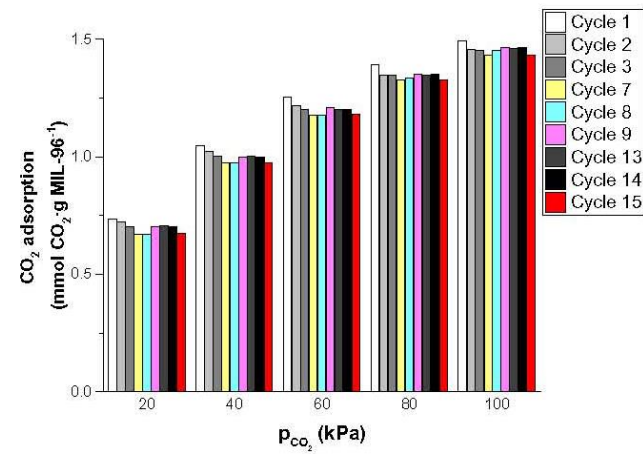

Fig. 11. $\mathrm{CO}_{2}$ uptakes on a recently prepared MIL-96(Al) LB film at different $\mathrm{CO}_{2}$ partial pressures during 15 adsorption/desorption cycles. Legend colors correspond to the adsorption cycle number. (For interpretation of the references to colour in this figure legend, the reader is referred to the web version of this article.)

performed with aged $\mathrm{LB}$ samples and lower $\mathrm{CO}_{2}$ uptakes were obtained at each $\mathrm{CO}_{2}$ partial pressure step, as it could be expected (Supplementary material, Figs. S11 and S12). Interestingly, the aged LB films exhibited similar performance than the asprepared LB samples, in terms of adsorption/desorption reversibility and reproducibility. These experiments show that MOF LB films are stable during several $\mathrm{CO}_{2}$ adsorption/desorption cycles. Moreover, $\mathrm{CO}_{2}$ can be desorbed simply by flowing an inert gas at 303 $\mathrm{K}$, without any thermal treatment and without a significant loss of the adsorption capacity of the films, confirming that a moderate adsorption enthalpy of the adsorbate is a relevant parameter that should be considered in the development of MOF based-devices for gas sensing or gas separations [20].

\section{Conclusions}

The formation of ultrathin films of NPs (size $200 \pm 50 \mathrm{~nm}$ ) of the metal organic framework MIL-96(Al) at the air-water interface has been optimized. The use of diluted $\left(0.2 \mathrm{mg} \mathrm{mL}^{-1}\right)$ MOF suspensions in chloroform prepared using ultrasonic probe leads to the formation of dense monolayers, without NP agglomeration, that can be transferred directly onto solid substrates of different nature (glass, quartz, silicon) as confirmed by SEM, UV-Vis and GIXRD characterization. This procedure provides a significant advantage compared to other methods used for MOF thin film preparation [14], since no substrate functionalization is required; moreover, it was not necessary to add any surfactant to MIL-96(AI) NPs to obtain dense monolayers onto OCM substrates, contrarily to the behavio observed for MIL-101(Cr) NPs that required behenic acid to be efficiently transferred onto these substrates used for gas adsorption studies [15].

Using a QCM-based device, a comparative $\mathrm{CO}_{2}$ adsorption study at $303 \mathrm{~K}$ has been performed on LB, LS and drop-cast films. MIL-96 (AI) films prepared and stored under different conditions have been analyzed, showing that film adsorption capacity strongly depends on the sample history (solvent used in suspension preparation, film fabrication method, storage conditions). Interestingly, it has been shown that $\mathrm{CO}_{2}$ uptakes, at $\mathrm{CO}_{2}$ partial pressures between 20 and $100 \mathrm{kPa}$, can be determined utilizing QCM substrates covered with just one LB monolayer. Moreover, a green and simple treatment just after film fabrication (immersion of the films during $12 \mathrm{~h}$ into water) increased by $30 \%$ the $\mathrm{CO}_{2}$ adsorption capacity of $\mathrm{LB}$ monolayers. Finally, $\mathrm{CO}_{2}$ adsorption/desorption 
experiments showed that MIL-96(AI) LB films are stable at least for 15 cycles, with a constant $\mathrm{CO}_{2}$ adsorption capacity and, more importantly, $\mathrm{CO}_{2}$ can be completely desorbed from the films at $303 \mathrm{~K}$ using only He flow during 20 min without heating the experimental setup. These results reveal that, although MIL-96(AI) shows a good affinity for $\mathrm{CO}_{2}$, the moderate adsorption enthalpy of $\mathrm{CO}_{2}$ onto this $\mathrm{MOF}$, facilitates the reversibility of the adsorption/desorption processes [22].

These results pave the way for new perspectives on the fabrication, characterization and applications of robust MOF thin films, especially for gas adsorption processes and devices based on very small amounts of MOFs that can be easily reused using a costeffective treatment at room temperature, without the need of aggressive regeneration procedures $[33,34]$. This methodology is particularly interesting for the development of gas sensors based on MOF thin films.

\section{Acknowledgements}

The research leading to these results has received funding from the European Union Seventh Framework Programme (FP7/2007-2013) under grant agreement number 608490 , project $\mathrm{M}^{4} \mathrm{CO}_{2}$; and also financial support from Spanish MINECO and FEDER (project MAT2016-78257-R), from the Universidad de Zaragoza (Project JIUZ-2015-CIE-02), the Aragon Government (DGA) and the ESF (research group E54). Miguel A. Andrés wants to acknowledge the support of Ministerio de Educación from the Spanish Government under a FPU grant (Formación de Profesorado Universitario).

The authors acknowledge the use of the Servicio General de Apoyo a la Investigación-SAI (Universidad de Zaragoza) and the Laboratorio de Microscopías Avanzadas (LMA) at the Instituto de Nanociencia de Aragón (INA, Universidad de Zaragoza), LMA-INA, for offering access to their instruments and expertise. The authors thank Dr. Carlos Cuestas for technical support in the SEM image acquisition and Dr. Guillermo Antorrena for assistance in GIXRD experiments. Prof. Dr. Joaquin Coronas, Prof. Dr. Carlos Tellez, Dr. Beatriz Zornoza and Javier Sanchez-Lainez are thanked for fruitful discussions about MOF films activation.

\section{References}

[1] P. Silva, S.M.F. Vilela, J.P.C. Tome, F.A.A. Paz, Multifunctional metal-organic frameworks: from academia to industrial applications, Chem. Soc. Rev. 44 frameworks: from

[2] G. Maurin, C. Serre, A. Cooper, G. Ferey, The new age of MOFs and of their porous-related solids, Chem. Soc. Rev. 46 (2017) 3104-3107.

[3] G. Ferey, Hybrid porous solids: past, present, future, Chem. Soc. Rev. 37 (2008) 191-214.

4] W.G. Lu, Z.W. Wei, Z.Y. Gu, T.F. Liu, J. Park, J. Park, I. Tian, M.W. Zhang, Q. Zhang T. Gentle, M. Bosch. H.C. Zhou, Tuning the structure and function of metal organic frameworks via linker design, Chem. Soc. Rev. 43 (2014) 5561-5593. 5] H. Furukawa, K.E. Cordova, M. O'Keeffe, O.M. Yaghi, The chemistry and applications of metal-organic frameworks, Science 341 (2013) 974

Engineering the surface of a new class of adsorbents: Metal-organic framework/graphite oxide composites, J. Colloid Interface Sci 447 (2015) 139-151.

[7] A.M. Fracaroli, H. Furukawa, M. Suzuki, M. Dodd, S. Okajima, F. Gandara, J.A. Reimer, O.M. Yaghi, Metal-organic frameworks with precisely designed
interior for carbon dioxide capture in the presence of water, J. Am. Chem. Soc. 136 (2014) 8863-8866.

[8] Z.Y. Yeo, S.P. Chai, P.W. Zhu, A.R. Mohamed, An overview: synthesis of thin films/membranes of metal organic frameworks and its gas separation performances, RSC Adv. 4 (2014) 54322-5433

[9] A.M. Rasero-Almansa, A. Corma, M. Iglesias, F. Sanchez, Design of a bifunctional Ir-Zr based metal-organic framework heterogeneous catalyst for the N-
alkylation of amines with alcohols, Chemcatchem 6 (2014) 1794-1800.
[10] A. Betard, R.A. Fischer, Metal-organic framework thin films: from fundamentals to applications, Chem. Rev. 112 (2012) 1055-1083.

111 P. Horcajada T. Chalati, C. Serre, B. Gillet, C. Sebrie, T. Baati, J.F. Eubank, D. Heurtaux, P. Clayette, C. Kreuz, J.S. Chang, Y.K. Hwang, V. Marsaud, P.N. Bories franewer imaging, Nat. Mater. 9 (2010) 172-178.

[12] V. Stavila, A.A. Talin, M.D. Allendorf, MOF-based electronic and optoelectronic devices, Chem. Soc. Rev. 43 (2014) 5994-6010.

13] P. Falcaro, R. Ricco, C.M. Doherty, K. Liang, A.J. Hill, M.J. Styles, MOF positioning technology and device fabrication, Chem. Soc. Rev. 43 (2014) 5513-5560.

[14] J.L. Zhuang. A. Terfort, C. Woll, Formation of oriented and patterned films of metal-organic frameworks by liquid phase epitaxy: a review, Coord. Chem Rev. 307 (2016) 391-424.

[15] J. Benito, S. Sorribas, I. Lucas, J. Coronas, I. Gascon, Langmuir-Blodgett films of the metal-organic framework MIL-101(Cr): preparation, characterization, and (2016) $16486-16492$

[16] L. Heinke, M. Tu S. Wannapaiboon, R.A. Fischer, C. Wöll, Surface-mounted metal-organic frameworks for applications in sensing and separation Microporous Mesoporous Mater. 216 (2015) 200-215.

17] L. Heinke, Z.G. Gu, C. Woll, The surface barrier phenomenon at the loading of metal-organic frameworks, Nat. Commun. 5 (2014) 4562-4567.

[18] C. Chmelik, F. Hibbe, D. Tzoulaki, L. Heinke, J. Caro, J. Li, J. Kărger, Exploring the nature of surface barriers on MOF $\mathrm{Zn}($ tbip) by applying IR microscopy in high temporal and spatial resolution, Microporous Mesoporous Mater. 129 (2010)

[19] T. Loiseau, L. Lecroq, C. Volkringer, J. Marrot, G. Fêrey, M. Haouas, F. Taulelle, S. Bourrelly, P.L. Llewellyn, M. Latroche, MIL-96, a porous aluminum trimesate

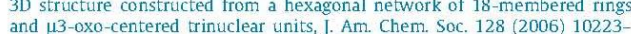
10230

[20] M. Benzaqui. R.S. Pillai, A. Sabetghadam, V. Benoit. P. Normand, J. Marrot. N. Menguy. D. Montero. W. Shepard, A. Tissot, C. Martineau-Corcos. C. Sicard, M. Mihaylov, F. Carn, I. Beurroeis, P.L. Llewellyn, G. De Weireld, K. Hadjiivanov, J. Gascon, F. Kapteijn, G. Maurin, N. Steunou, C. Serre, Revisiting the aluminum trimesate-based MOF (MIL-96): from structure determination to the processing of mixed matrix membranes for $\mathrm{CO}_{2}$ capture, Chem. Mater. 29 (2017) 10326-1033

[21] K. Adil, Y. Belmabkhout, R.S. Pillai, A. Cadiau, P.M. Bhatt, A.H. Assen, G. Maurin M. Eddaoudi, Gas/vapour separation using ultra-microporous metal-organic frameworks: insights into

2) N. Chanut, S. Bourrelly, B. Kuchta, C. Serre, J-S. Chang, P.A. Wright, P.L Llewellyn, screening the effect of water vapour on gas adsorption perfomance: application to $\mathrm{CO}_{2}$ capture from
frameworks, Chemsuschem 10 (2017) 1543-1553.

23| A. Venkatasubramanian, M. Navaei, K.R. Bagnall, KC. McCarley, S. Nair, P.J. Hesketh, Gas adsorption characteristics of metal-organic frameworks via quartz crystal microbalance techniques, J. Phys. Chem. C 116 (2012) 1531315321

[24] J.S. Taurozzi, V.A. Hackley, M.R. Wiesner, Ultrasonic dispersion of nanoparticles for environmental, health and safety assessment - issues and recom

Power of Ultrasound Ultrasound in Chemistry. Wiley-VCH Verlag GmbH \& Co. KGaA2009, pp. 1-16.

[26] J.A. Thompson, KW. Chapman, W.J. Koros, C.W. Jones, S. Nair, Sonicationinduced Ostwald ripening of ZIF-8 nanoparticles and formation of ZIF-8/ 292-299.

[27] T. Shimoaka, Y. Tanaka, N. Shioya, K. Morita, M. Sonoyama, H. Amii, T. Takag, T. Kanamori, T. Hasegawa, Surface properties of a single perfuoroalkyl group on water surfaces studied by surface potential measurements, J. Colloid Interface Sci. 483 (2016) 353-359.

[28] T.-Q. Lu, K.-R. Ma, C. Zhao, Y.-Y. Gu, H.-Q. Su, R.-Q. Li, Solvothermal synthesis crystal structure and properties of a new bisphosphonic-trimesic acid adduct,

29] R.K. Vakiti, B.D. Garabato, N.P. Schieber, M.J. Rucks, Y. Cao, C. Webb, J.B. MaddoX, A. Celestian, W.-P. Pan, B. Yan, Synthesis and characterization of two 1.3.5-tricarboxylate and/or pyrazine-2-carboxylate, Cryst. Growth Des, 12 (2012) 3937-3943

30| G. Sauerbrey, Verwendung von Schwingquarzen zur Wägung dünner Schichten und zur Mikrowägung, Z. Phys. 155 (1959) $206-222$.

31 R. Catlow, A. Sokol, A. Walsh, Computational Approaches to Energy Materials, Wiley, 2013, p. 205.

32] G.A. Gonzalez-Martinez, J.A. Zarate, A. Martinez, E. Sanchez-Gonzalez, J.R Alvarez, E. Lima, E. Gonzalez-Zamora. I.A. Ibarra, Confinement of alcohols to enhance $\mathrm{CO}_{2}$ capture in MIL-53(Al), RSC Adv. 7 (2017) 24833-24840.

[33] M.W. Hahn, J. Jelic, E. Berger, K Reuter, A. Jentys, J.A. Lercher, Role of amin 1988-1995.

[34] Y. Cao, Y. Zhao, Z. LV, F. Song, Q. Zhong, Preparation and enhanced $\mathrm{CO}_{2}$ adsorption capacity of Uio-66/graphene oxide composites, J. Ind. Eng. Chem. 27 (2015) 102-107. 